\title{
Acute fatty liver of pregnancy: A review of maternal morbidity in 13 patients seen over 12 years in Nova Scotia
}

\author{
CONNIE D HOARE MD FRCPC, DICKRAN A MALATJALIAN MD FACP, BERNARD W BADLEY MD FRCPC, \\ JOSEPH J SIDOROV MD FRCPC, C NOEL WILLIAMS MD FRCPC
}

CD Hoare, DA Malatjalian, BW Badley, JJ Sidorov, CN Williams. Acute fatty liver of pregnancy: A review of maternal morbidity in 13 patients seen over 12 years in Nova Scotia. Can J Gastroenterol 1994;8(2):81-87.

OBJECTIVE: To review the maternal and fetal survival in all cases of acute fatty liver of pregnancy seen by the Division of Gastroenterology at Grace Maternity Hospital and the Victoria General Hospital from 1979-91.

DESIGN: A retrospective review of the clinical data obtained from the medical charts of 13 patients with a liver biopsy-based histopathological diagnosis of acute fatty liver of pregnancy.

SeTTING: Grace Maternity Hospital, a tertiary care centre serving the Atlantic provinces. Twelve patients were subsequently transferred to Victoria General Hospital for postpartum management in the setting of the medical intensive care unit. MAIN OUTCOME MEASURES: Classically, acute fatty liver of pregnancy is complicated by over $70 \%$ maternal and fetal mortality rate. Recent reports have indicated significantly improved maternal and fetal survival because of more awareness, improved management and the identification of milder forms of the disease.

RESULTS: In this study of 13 cases of acute fatty liver of pregnancy, maternal survival was $100 \%$ and fetal survival was $93 \%$.

CONCLUSION: The excellent maternal and fetal survival in this series is attributed to awareness, close collaboration between obstetricians and gastroenterologists, prompt diagnosis and delivery and the management of postpartum patients in an intensive care unit setting.

Key Words: Acute fatty liver of pregnancy, Management, Pathology, Prognosis

Stéatose gravidique : étude de la morbidité maternelle chez 13 patientes vues en Nouvelle-Écosse sur une période de 12 ans

OBJECTIF : Passer en revue les taux de survie maternelle et foetale dans tous les cas de stéatose gravidique observés au département de gastroentérologie du Grace

continued on next page

Divisions of Gastroenterology and Pathology, Victoria General Hospital; and Dalhousie University, Halifax, Nova Scotia

Correspondence and reprints: Dr DA Malatjalian, Department of Pathology, Victoria General Hospital, 1278 Tower Road, Halifax, Nova Scotia B3H 2Y9. Telephone (902) 428-3892, Fax (902) 428-3978

Received for publication June 12, 1993. Accepted December 12, 1993
AUNDICE OCCURS IN ABOUT ONE IN
1500 pregnancies (1-3), and may
either be related specifically to the pregnancy or be coincidental. Acute viral hepatitis ( $A, B, C)$ accounts for 40 to $60 \%$ of all cases of jaundice in pregnancy $(4,5)$. Hepatitis E occurs most commonly in developing countries, and has been associated with increased mortality rate during the third trimester of pregnancy (6). Other less common coincidental liver diseases in pregnancy include biliary obstruction, exacerbation of previously unrecognized chronic hepatitis, decompensation of asymptomatic cirrhosis and drug-induced hepatitis $(4,5,7-9)$.

The causes of pregnancy-specific jaundice include benign cholestasis of pregnancy, preeclampsia, hyperemesis gravidarum and acute fatty liver of pregnancy, the latter accounting for less than $10 \%$ of all causes of jaundice in pregnancy $(4,5)$.

Acute fatty liver of pregnancy, first described by Sheehan (10), was considered an uncommon cause of fulminant hepatitis occurring in the third trimester of pregnancy and resulting in high maternal and fetal death rates (10-17). Most cases of acute fatty liver of pregnancy occur between 36 and 40 weeks, but it has been reported to occur as early as 22 to 24 weeks of gestation $(4,5,18)$. Few cases have occurred in early puerperium (16). Histologically, the liver characteristically shows micro- 


\begin{abstract}
Maternity Hospital et du Victoria General Hospital entre 1979 et 1991.
MODÈLE : Étude rétrospective des données cliniques obtenues de dossiers médicaux de 13 patientes ayant eu un diagnostic histopathologique de stéatose gravidique à partir de biopsies.

CONTEXTE : Grace Maternity Hospital, centre hospitalier de soins tertiaires, qui dessert les provinces de l'Atlantique. Douze patientes ont par la suite été transférées au Victoria General Hospital pour traitement post-partum dans une unité de soins intensifs.

ÉPIDÉMIOLOGIE : De façon classique, la stéatose gravidique est compliquée par des taux de mortalité supérieurs à $70 \%$ chez la mère et le foetus. Selon des rapports récents, ce taux de survie s'est nettement amélioré à cause d'une plus grande sensibilisation au problème, d'un meilleur traitement et de l'identification de formes plus bénignes de la maladie.

RÉSULTATS : Dans cette étude, sur 13 cas de stéatose gravidique, le taux de survie maternelle a été de $100 \%$ et le taux de survie foetale de $93 \%$.

CONCLUSION : Les taux de survie maternelle et foetale excellents observés dans cette série sont attribués à la sensibilisation au problème, à la proche collaboration entre obstétriciens et gastroentérologues, au diagnostic et à l'accouchement rapides et au traitement post-partum des patientes dans une unité de soins intensifs.
\end{abstract}

vesicular steatosis due to accumulation mainly of intracytoplasmic lipids $(19,20)$. Variable degrees of hepatocellular degeneration and necrosis occur, depending on the severity of the disease, but inflammation is usually absent or minimal $(21,22)$.

Treatment of acute fatty liver of pregnancy consists of prompt termination of the pregnancy followed by supportive care $(4,5,7)$ to control the hypoglycemia, coagulopathy, encephalopathy and renal failure. With earlier diagnosis, delivery and better supportive care, the reported maternal and fetal mortality rate of acute fatty liver of pregnancy has decreased from over $70 \%$, to 10 to $33 \%$ in recent clinicopathological series $(10,12,14,16,23$. 26). Orthotopic liver transplantation has been used in one case of severe acute fatty liver of pregnancy (24).

\section{MATERIALS AND METHODS}

The authors retrospectively reviewed hospital charts to obtain the case histories' clinical and laboratory features, and treatments of all patients with biopsy-proven acute fatty liver of pregnancy from 1979 to 1991 in the Grace Maternity Hospital in Halifax, Nova Scotia, in consultation with the Division of Gastroenterology at Victoria General Hospital in Halifax. Grace Maternity Hospital serves as the only centre for deliveries in metropoli- tan Halifax-Dartmouth (population $300,000)$. It also serves as a referral centre for high risk pregnancies for the Maritime provinces. All mothers with acute fatty liver of pregnancy survived and, with the exception of one death due to prematurity, all 15 babies survived.

\section{CASE HISTORY PRESENTATIONS}

The clinical, laboratory data and the liver biopsy findings are summarized in Tables 1 to 3 . Cases 1 to 4 have been reported previously $(21,22)$.

Case 1: A 31-year-old multipara was admitted at 32 weeks' gestation with a 10-day history of anorexia, fatigue, and nausea followed by upper abdominal pain, vomiting, $6.6 \mathrm{~kg}$ weight loss and nonpruritic jaundice two days before admission. There was no past history of liver disease, hepatotoxins or parenteral exposure. On admission the liver was tender and palpable $1 \mathrm{~cm}$ below the right costal margin. The following day the liver was not palpable, and there was fetor hepaticas and asterixis. The patient underwent an urgent caesarean section the day following admission for fetal distress, liver dysfunction and coagulopathy. She was transferred postoperatively to the intensive care unit where she recovered after a stormy course complicated by staphylococcal pneumonia, cerebral edema, hypogly- cemia and coagulopathy. The patient was discharged home 28 days later. She later underwent surgical sterilization. Case 2: A 23-year-old primigravida was admitted at 39 weeks' gestation with a two-week history of nausea, vomiting and leg edema. Physical examination revealed a jaundiced pregnant female with normal vital signs and pitting edema to her knees. Urinalysis was negative. She spontaneously delivered a healthy male. Three days postpartum, the patient developed signs of rapid liver failure with bloody ascites and ileus. She was transferred to the intensive care unit for further supportive care. She was drowsy and short of breath on arrival. Physical examination revealed asterixis, fetor hepaticas, ascites and hepatomegaly. She recovered and was discharged 19 days later.

Case 3: A 22-year-old primigravida was admitted at full term with a seven-day history of nausea, vomiting, epigastric pain and jaundice. One day before delivery she noted vaginal bleeding. Following delivery of a female baby in fetal distress with meconium staining, the patient developed oozing from intravenous sites and vaginal bleeding. She was transferred to Victoria General Hospital. On admission, she was oliguric and hypotensive. Physical examination was normal apart from a shrunken liver. The patient was given intensive supportive care, with complete recovery in 17 days.

Case 4: A 34-year-old multiparous female with a history of herpes gestationalis in the first trimester of present pregnancy treated with prednisone and pyridoxine was admitted at 28 weeks' gestation with premature rupture of the membranes. Serum transaminases were elevated on admission. Physical examination was otherwise normal. She went into spontaneous breech labour and was delivered by caesarean section for fetal distress. Her postoperative course was uneventful and she was discharged 11 days later.

Case 5: A 24-year-old primigravida was admitted at 33 weeks' gestation with preterm labour. Four days before admission, she developed nausea, vomiting, anorexia, jaundice, epigastric pain and hematemesis. On physical examination 


\section{TABLE 1}

Clinical details of patients

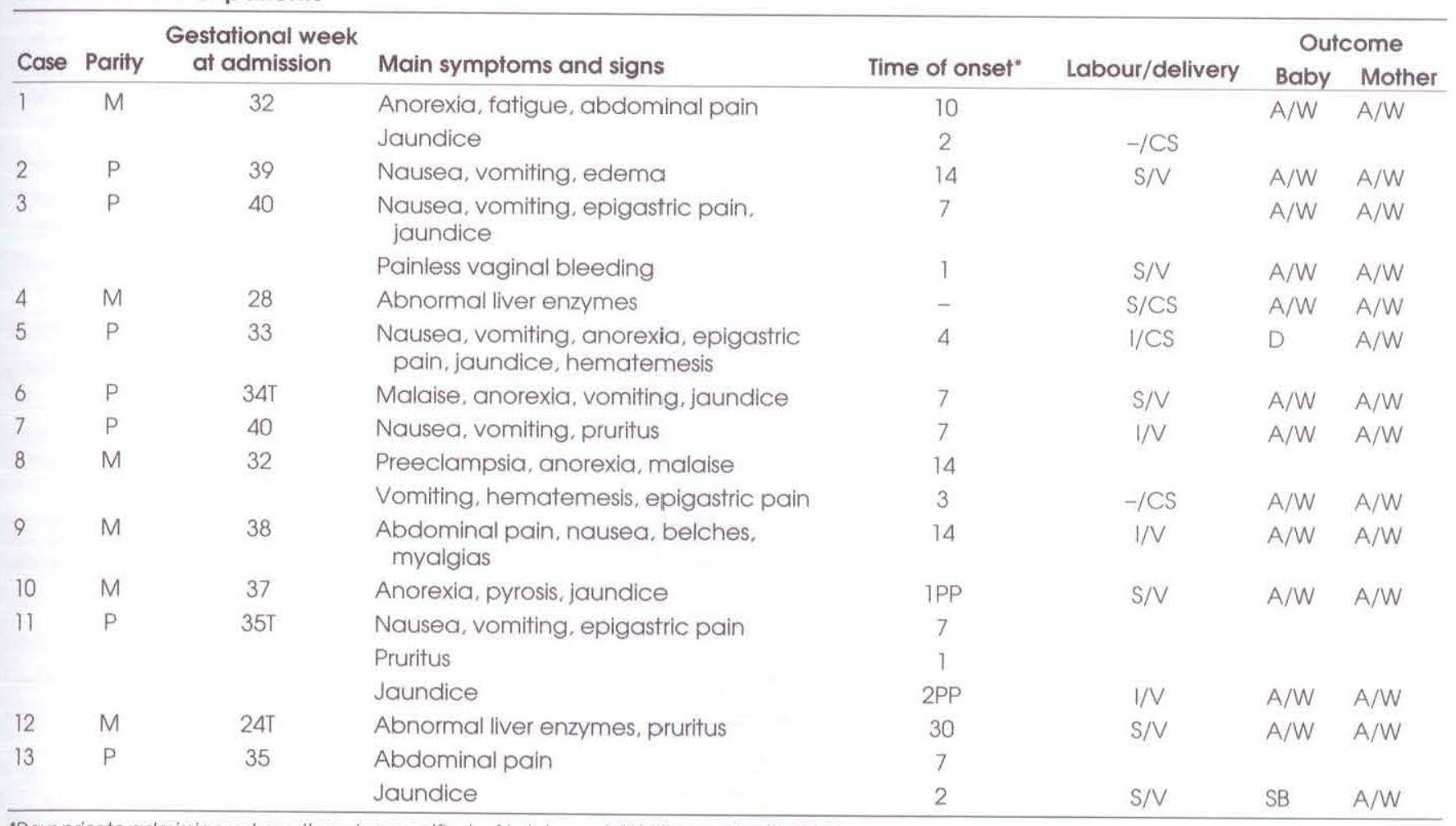

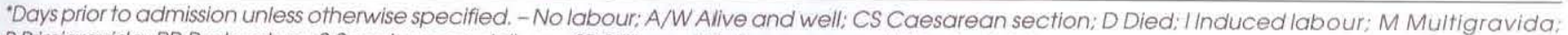
P Primigravida; PP Postpartum; S Spontaneous delivery; SB Stillborn; T Twin pregnancy; V Vaginal dellvery

she was drowsy, had right upper quadrant tenderness, leg edema, hyperreflexia and asterixis. Her blood pressure was $140 / 110 \mathrm{mmHg}$. There was no hepatosplenomegaly. A caesarean section was done on the day of admission for fetal distress. The patient was transferred to Victoria General Hospital's intensive care unit for supportive care. The infant died at 14 days of congestive heart failure, intracerebral hemorrhage, renal failure, bone marrow failure and liver dysfunction. The mother's course was complicated by encephalopathy, coagulopathy, hypertension and wound hematoma. The patient recovered and was discharged home 20 days later.

Case 6: A 30-year-old primigravida with a twin pregnancy was admitted at 34 weeks' gestation with a seven-day history of malaise, fatigue, anorexia, vomiting and jaundice. On admission, she was afebrile. Physical examination was normal except for brisk reflexes. Four days after admission, the patient developed spontaneous labour with delivery of twins. Following delivery she was transferred to Victoria General
Hospital's intensive care unit. She recovered completely and was discharged 15 days later.

Case 7: A 21-year-old primigravida was admitted at 40 weeks' gestation with a seven-day history of nausea, vomiting, constipation and pruritus. Physical examination on admission was normal except for a blood pressure of 120/94 $\mathrm{mmHg}$. She underwent medical induction for hepatic dysfunction and hypertension. She delivered a healthy female. The patient recovered without any difficulty. She was discharged 10 days later. Five years later she delivered a healthy female without any complications.

Case 8: A 32-year-old multipara was transferred at 32 weeks' gestation for induction for hypertension. She had a two-week history of anorexia and malaise. Vomiting, epigastric pain and hematemesis developed three days before admission. On admission she was given magnesium sulphate infusion, ranitidine and dimenhydrinate suppositories. Physical examination revealed a jaundiced female with a tender liver palpa- ble $2 \mathrm{~cm}$ below the right costal margin, leg edema, brisk reflexes and blood pressure of $160 / 90 \mathrm{mmHg}$. Peripheral blood smear demonstrated few red blood cell fragments, suggesting intravascular hemolysis. Platelet count was normal. Urinalysis was negative. A caesarean section was done for fetal distress. The patient was transferred to Victoria General Hospital's intensive care unit where she was given supportive therapy for pulmonary edema and coagulopathy. She recovered well and was discharged home 11 days later. At followup eight weeks later, she was feeling well except for fatigue.

Case 9: A 27-year-old multipara was admitted at 38 weeks' gestation with abdominal pain, nausea, vomiting, belching and myalgia. On admission she was jaundiced, confused, and had fetor hepaticas and asterixis. There was leg edema to her knees and hyperactive deep tendon reflexes. Her blood pressure was normal. The patient underwent medical induction and delivery for liver dysfunction and coagulopathy. She was transferred to Victoria General 
TABLE 2

Laboratory findings on admission

\begin{tabular}{|c|c|c|c|c|c|c|c|c|c|}
\hline Case & $\begin{array}{l}\text { WBC } 10^{9} / \mathrm{L} \\
(4.5-10.5)\end{array}$ & $\begin{array}{l}\mathrm{HGB} \mathrm{g} / \mathrm{L} \\
(130-175)\end{array}$ & $\begin{array}{l}\text { Platelets } 10^{9} / \mathrm{L} \\
(150-350)\end{array}$ & PT* & $\begin{array}{l}\text { AST U/L } \\
(8-29)\end{array}$ & $\begin{array}{l}\text { ALT U/L } \\
(8-29)\end{array}$ & $\begin{array}{l}\text { ALP U/L } \\
(30-104)\end{array}$ & $\begin{array}{c}\text { Bilirubin total/direct } \\
\mu \mathrm{mol} / \mathrm{L}(0-16 / 0-4)\end{array}$ & $\begin{array}{l}\text { Uric } \\
\text { acid }\end{array}$ \\
\hline 1 & 24.3 & 88 & 84 & 16.5 & 74 & - & 582 & $183 /-$ & 66 \\
\hline 2 & 23 & 86 & 153 & 18 & 94 & 152 & 591 & $171 / 86$ & - \\
\hline 4 & 13 & 136 & - & - & 163 & 700 & 102 & $15 /-$ & - \\
\hline 5 & 25 & 111 & 68 & 14.5 & 340 & 389 & 389 & $127 / 77$ & 650 \\
\hline 8 & 28 & 146 & 215 & 14.6 & 203 & 369 & 490 & $62 / 38$ & 725 \\
\hline 9 & 29 & 143 & 170 & 15 & 304 & 311 & 499 & $155 / 108$ & 689 \\
\hline 10 & 13 & 164 & 131 & 12.5 & 115 & 85 & 402 & $119 / 74$ & - \\
\hline 11 & 31 & 81 & 146 & 16.5 & 74 & 131 & 429 & $97 / 63$ & - \\
\hline 12 & 12.6 & 118 & 277 & 12 & 663 & 1315 & 173 & $10 / 2$ & 299 \\
\hline
\end{tabular}

Normal range appears in brackets. "Control value ranged from 10 to $12 \mathrm{~s}$; - Not measured; 'normal' Recorded as normal with no value entered. The controls for PT ranged from 10 to $12 \mathrm{~s}$. ALP Alkaline phosphatase: ALT Alanine aminotransferase; AST Aspartate aminotransferase; HGB Hemoglobin: PT Prothrombin time; WBC White blood cells

Hospital's intensive care unit for further supportive care. Her course was complicated by encephalopathy and hypoglycemia. She recovered and was discharged home 11 days later with only mildly abnormal liver enzymes. At follow-up four weeks later, she was doing well.

Case 10: A 35-year-old multipara was admitted at 37 weeks' gestation in spontaneous labour. Her pregnancy was complicated only by pyrosis. On the day of delivery, the patient developed anorexia and heartburn, and one day later she became jaundiced. Hepatic 2,6-dimethyl-iminodiacetic acid scan and ultrasound were normal. She recovered and was discharged home nine days later.

Case 11: A 35-year-old primigravida was admitted at 35 weeks' gestation with a seven-day history of nausea, vomiting and epigastric pain. While in hospital, she complained of pruritus. Delivery of twins was induced for nonreactive stress tests. Two days postdelivery, she developed jaundice, vomiting, periumbilical bruising, vaginal bleeding and ileus. She was transferred to the intensive care unit at Victoria General Hospital for supportive care for liver dysfunction and coagulopathy. She recovered quickly and was discharged home 12 days later.

Case 12: A 27-year-old multipara was admitted at 24 weeks' gestation. Her pregnancy had been complicated by obesity and gestational diabetes. At 28 weeks of gestation, while in hospital, she developed abnormal liver enzymes and pruritus. Viral serology for hepatitis $\mathrm{A}, \mathrm{B}$ and $\mathrm{C}$ and for human immunodeficiency virus (HIV) were negative. Abdominal ultrasound and liver scan were negative. She underwent spontaneous vaginal delivery of twins at 34 weeks' gestation. Her liver enzymes deteriorated again seven days postpartum. At discharge, 18 days later, she had normal liver enzymes and felt well.

Case 13: A 24-year-old primigravida presented to her local hospital at 35 weeks' gestation with abdominal pain thought to be due to a urinary tract infection. She developed a rash and became jaundiced while on ampicillin. She delivered a stillborn fetus at 36 weeks. Four days postpartum, the patient was found comatose and hypotensive, with abnormal liver enzymes. She was resuscitated at the local hospital. Her ultrasound showed a fatty liver. Her hemoglobin was low and she had coagulopathy. The patient was intubated, given pancuronium bromide and transferred to Victoria General Hospital's intensive care unit for supportive care. A repeat ultrasound showed ascites and normal hepatopedal flow. Computed tomographic scan of the brain was normal. Viral serology was negative. An intracranial pressure monitor was in- serted and she was referred for assessment for an orthotopic liver transplantation. However, within $72 \mathrm{~h}$ she was sitting up and talking coherently. She did well without a transplant and was discharged. A few weeks later, she was admitted to hospital for tonic-clonic seizures. Computed tomographic scan showed a right frontoparietal abnormality, likely due to the intracranial pressure monitor. She was treated successfully with anticonvulsants.

\section{RESULTS}

The clinical and laboratory data on the 13 patients are shown in Tables 1 to 3. Seven patients were primigravida and six multigravida, the latter with no previous pregnancy-associated liver disease.

The age range of the 13 patients was 21 to 35 years, mean 28 . The illness began in the antepartum period in all 13 patients at 28 to 40 weeks' gestation. The most common presenting complaints were anorexia, nausea, vomiting and abdominal pain. Clinical jaundice developed in seven patients; in two, jaundice manifested one and two days postpartum. Pruritus was a major complaint in three patients. Three patients (cases 5, 7 and 8 ) were hypertensive, two with a trace of proteinuria and one without. One patient (case 4) was completely asymptomatic but was found to have abnormal liver enzymes. 
None of the patients had history of excess alcohol intake, previous transfusions, exposure to hepatotoxic drugs or contact with jaundiced patients during their pregnancy.

The laboratory data at the time of diagnosis of acute fatty liver of pregnancy revealed leukocytosis in all patients, range 12,000 to $31,000 \mathrm{~mm}^{3}$. The platelet count was below $100,000 / \mathrm{mm}^{3}$ in five patients at admission. In some of the other patients, the platelet count fell after admission. Serum transaminases were elevated in all patients. The elevation in aspartate aminotransferase (AST) was mild to moderate (less than 10-fold increase) in 10 patients and markedly elevated in three. Alanine aminotransferase (ALT) was within normal range in two patients, mild to moderately elevated (less than 10-fold) in five and markedly elevated (10-fold or greater) in five. Serum ALT was not recorded in one patient. The total bilirubin level ranged from 10 to $183 \mu \mathrm{mol} / \mathrm{L}$ and direct bilirubin from 2 to $137 \mu \mathrm{mol} / \mathrm{L}$.

Serological investigation for hepatitis $B$ virus was done in seven patients, for hepatitis $\mathrm{C}$ in two patients, for hepatitis A in two, for Epstein-Barr virus in four and for HIV in one. All were negative except for case 4 , who had a positive hepatitis $A$ immunoglobulin $G$ antibody.

Liver biopsies were obtained from all 13 patients in the postpartum period (Table 3). All biopsies showed the characteristic finding of microvesicular steatosis. All but one of the biopsies revealed variable degrees of hepatocellular degeneration and necrosis. Bridging necrosis with reticulin framework collapse was seen in three patients. Electron microscopic examination of the liver was conducted on biopsies from five patients. These showed microvesicular steatosis and the characteristic mitochondrial damage.

Labour occurred spontaneously in seven patients and was medically induced in four. The indication for induction of labour was a nonreactive stress test in one; fetal distress in one; hypertension in two, and the clinical diagnosis of acute fatty liver of pregnancy in two. Four patients underwent caesar-

TABLE 3

Light microscopic findings in liver biopsies

\begin{tabular}{|c|c|c|c|c|c|c|}
\hline \multirow[b]{2}{*}{ Case } & \multirow{2}{*}{$\begin{array}{c}\text { Microvesicular } \\
\text { steatosis }\end{array}$} & \multirow[b]{2}{*}{ Degeneration" } & \multirow[b]{2}{*}{ Necrosis $^{\dagger}$} & \multirow[b]{2}{*}{ Cholestasis* } & \multicolumn{2}{|c|}{ Inflammation* } \\
\hline & & & & & Portal & Lobular \\
\hline 1 & + & +++ & +++ & +++ & + & + \\
\hline 2 & + & +++ & + & +++ & - & - \\
\hline 3 & + & + & + & - & - & - \\
\hline 4 & + & +++ & + & + & - & - \\
\hline 5 & + & + & + & + & - & - \\
\hline 6 & + & +++ & + & + & - & - \\
\hline 7 & + & + & + & + & - & - \\
\hline 8 & + & +++ & + & + & + & + \\
\hline 9 & +++ & +++ & +++ & + & - & + \\
\hline 10 & - & + & + & + & + & + \\
\hline 11 & + & +++ & +++ & + & - & + \\
\hline 12 & + & + & - & - & - & - \\
\hline 13 & + & + & + & +++ & + & + \\
\hline
\end{tabular}

- Absent: + Mild $;++$ Moderate $;+++$ Severe: ${ }^{\dagger}+$ Focal: ++ Confluent; +++ Bridging

ean sections for fetal distress. Three patients had twin pregnancies. One pregnancy (case 13) terminated with a stillborn.

Fourteen of the 15 live births survived. One 14-day-old infant died of prematurity (case 5).

All mothers survived and their liver enzymes became normal or near normal at discharge. One patient (case 1) had a follow-up liver biopsy one month after discharge from hospital; it showed focal mild residual fibrosis only. The authors are aware of two patients (cases 7 and 13) who went on to have second pregnancies that were uncomplicated.

\section{DISCUSSION}

The age and parity in this and other series reflect a normal obstetric population (27). Parity did not seem to have any predictive or predisposing factor since $46 \%$ of our patients were multigravida. None of these patients had had known pregnancy-associated liver disease with a previous pregnancy, and one patient's subsequent pregnancy was uneventful. This confirms the observation that acute fatty liver of pregnancy affects isolated pregnancies (28). Three of our 13 patients (23\%) had twin pregnancies, which is a rate much higher than the 6 and $11 \%$ previously reported by Rolfes (27) and Burroughs (29), respectively.

The classical clinical presentation of acute fatty liver of pregnancy is that of a nonspecific prodromal syndrome of nausea, vomiting and abdominal pain often followed by jaundice, pruritus, coagulopathy, hypoglycemia, hepatic encephalopathy and coma occurring in the third trimester. In a small number of patients, the disease manifests in the immediate postpartum period (16). The laboratory data are characterized by mild elevation of transaminases, elevated serum bilirubin, hyperuricemia, hypoglycemia (which may be profound), leukocytosis and prolonged prothrombin time. Renal failure and disseminated intravascular coagulation with gastrointestinal and postpartum bleeding may occur in more severe forms of the disease. Milder forms of acute fatty liver of pregnancy have been described in which the liver function tests are abnormal but with mild or no constitutional symptoms and with or without jaundice (30). Two of our patients did not develop jaundice or elevation of serum bilirubin. One patient was totally asymptomatic but was found to have elevated serum transaminases.

The main differential diagnosis of acute fatty liver of pregnancy includes preeclampsia/toxemia of pregnancy, hemolysis, elevated liver enzymes and low platelet count, alcohol-induced hepatitis, and viral hepatitis types A, B, $\mathrm{C}$ and $\mathrm{E}$ (6). Other conditions in the differential diagnosis include benign cholestasis of pregnancy and drug in- 


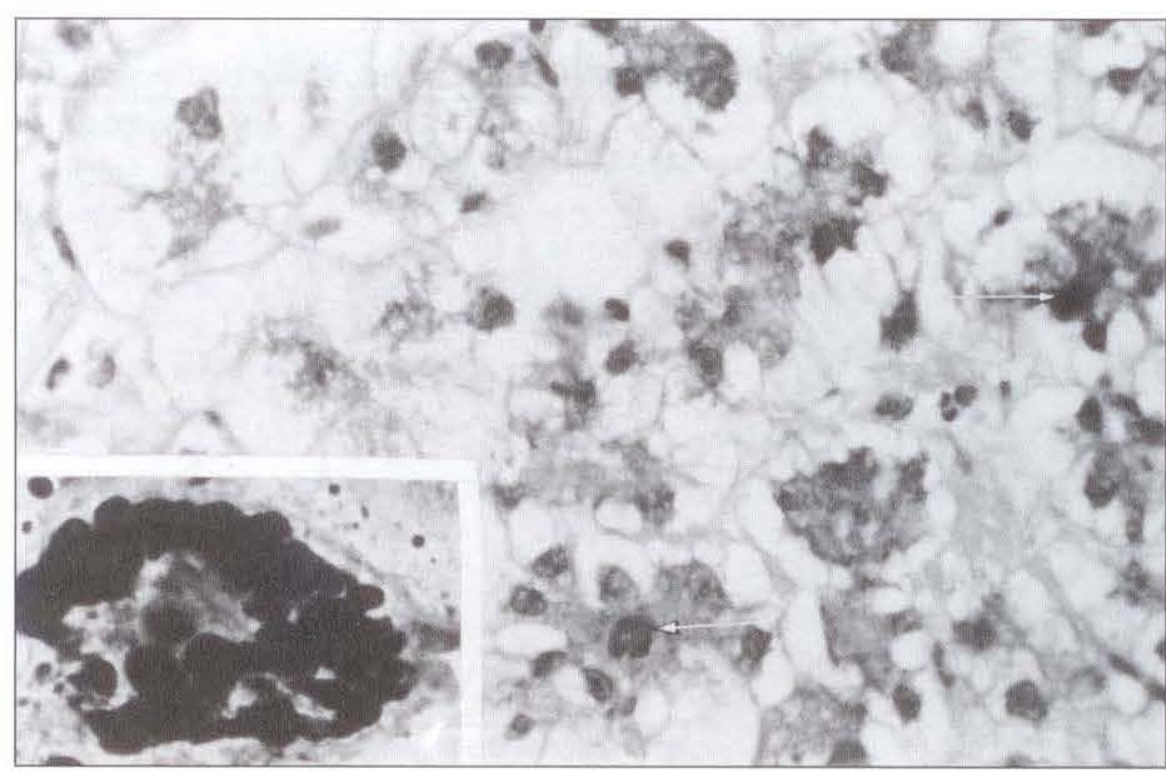

Figure 1) Photomicrograph of a histological section of liver biopsy from case 2 showing marked hydropic (ballooning) degeneration of hepatocytes and bile plugs in secondary canaliculi (arrows). The microvesiculation due to intracytoplasmic lipid is present but not easily seen (hematoxylin and $\operatorname{eosin} \times 2000$ ). The insert is from an oil-red-O stained section demonstrating the microvesicular intracy toplasmic fat droplets

duced hepatitis. Preeclampsia and the syndrome of hemolysis, elevated liver enzymes and low platelet count pose a special differential diagnostic challenge because of overlapping clinical, laboratory and histological features with acute fatty liver of pregnancy. Both conditions occur in the third trimester of pregnancy and both improve after delivery (31). Hypertension with proteinuria, which characterizes preeclampsia, is also found in 25 to $50 \%$ of patients with acute fatty liver of pregnancy (31). In addition, both groups tend to have elevated serum uric acid levels and low antithrombin III (32. 34). Microvesicular steatosis, characteristic of acute fatty liver of pregnancy, has also been described in the preeclampsia/eclampsia syndrome (35). In the latter, however, fibrin deposition in portal and periportal areas along with hemorrhage are observed, features not found in acute fatty liver of pregnancy (25). Indeed, it has been suggested that acute fatty liver of pregnancy is a severe form of liver disease in preeclampsia (35). In our series, only one patient (case 8) with hypertension and mild proteinuria was labelled 'preeclampsia'. The other two patients (cases 5 and 7), although borderline hypertensives, lacked other criteria for preeclampsia. In spite of some clinical and histopathological similarities, we believe preeclampsia and acute fatty liver of pregnancy are two distinct entities.

Viral hepatitis is reported as the most common cause of jaundice in pregnancy $(2,36)$ and its differentiation from acute fatty liver of pregnancy is important in the obstetrical management of the patient $(6,37,38)$. A caesarean section to terminate pregnancy may be detrimental to the critically ill patient with fulminant viral hepatitis. Serological tests for viral antigens are helpful but a negative test result does not necessarily exclude acute hepatitis $\mathrm{B}$ or $\mathrm{C}$ infections. The distinctive histological hepatic changes make a liver biopsy valuable in differentiating between viral hepatitis and acute fatty liver of pregnancy. However, the coagulopathy associated with fulminant hepatitis may pose a serious hindrance to obtaining a percutaneous needle liver biopsy. Not all centres have the expertise for a transjugular biopsy procedure. From a practical point, the urgency of the condition in the critically ill patient allows time for a clinical decision only. In general, the diagnosis of severe acute fatty liver of pregnancy is suggested by rapidly decreasing liver size, mild elevation of serum transaminase levels and hyperuricemia. By contrast, in acute viral hepatitis, the liver is enlarged, tender and the transaminase levels are markedly elevated. In patients with milder disease, further laboratory investigations and histological evaluations may be carried out.

In our series, liver biopsies were taken from 13 patients. Only in the two patients with mild disease (cases 10 and 12) were the biopsies antepartum. In the remainder, the diagnosis of acute fatty liver of pregnancy was suspected clinically, and biopsies were obtained postpartum for confirmation. The amount of microvesicular steatosis, hepatocellular degeneration and necrosis depends on the stage and severity of the disease at the time of biopsy. The presence of microvesicular steatosis can be determined by staining frozen sections with oil-red-O stain (Figure 1, insert). In our experience, however, examination of toluidine blue stained sections of tissue taken for electron microscopic examination was most helpful to identify microvesicular steatosis (Figure 1).

Earlier reports of acute fatty liver of pregnancy have shown high maternal and fetal mortality rates $(1,11,39,40)$. During the 12-year span of this study, we have had no maternal deaths and the only neonatal death occurred at 14 days of life due to immaturity. The other fetal loss was intrauterine at 35 weeks' gestation. We attribute our $100 \%$ maternal survival to early recog. nition and prompt delivery of patients with rapidly evolving liver failure and their management under a multidisciplinary team in an intensive care unit setting. The thrust of postpartum management is the correction of any hypoglycemia, coagulopathy and encephalopathy. Acute renal failure occurs in about $60 \%$ of patients with severe acute fatty liver of pregnancy $(41,42)$. Other extrahepatic complications that have been reported include pancreatitis (14), gastrointestinal bleeding $(14,23)$ and transient diabetes insipidus (43). Liver transplantation was reported in one patient with good results (44). One of our patients was considered for liver 
transplantation but she recovered spontaneously.

\section{CONCLUSIONS}

Acute fatty liver of pregnancy can present with variable severity and probably occurs more frequently than was initially thought. Its recognition rests largely on the awareness of the condition and its outcome depends on appropriate antepartum and postpartum management.

ACKNOWLEDGEMENTS: The authors are grateful to Ms Patsy Morgan for her help in preparing this manuscript. Dr C Hoare is a Fellow in the Division of Gastroenterology, Dalhousie University. Dr BWD Badley is President and Chief Executive Officer of the Victoria General Hospital, Halifax, Nova Scotia.

\section{REFERENCES}

1. Haemmerli UP. Jaundice during pregnancy, with special emphasis on recurrent jaundice during pregnancy and its differential diagnosis. Acta Med Scand Suppl 1966;444:1-111.

2. Haemmerli UP, Wyss II. Recurrent intrahepatic cholestasis of pregnancy. A report of six cases and review of the literature. Medicine 1967;46:299.

3. Hiatt JR, Hiatt JCG, Williams RA, et al. Biliary disease in pregnancy: strategy for surgical management. Am J Surg 1986;151:263-5.

4. Sherlock S. Jaundice in pregnancy. Br Med Bull 1968;24:39-43.

5. Haemmerli UP. Jaundice in pregnancy. In: Schiff L, ed. Diseases of Liver, 4th edn. Philadelphia: Lippincott, 1975:1336-53.

6. Khuroo M, Teli MR, Skidmore S, et al. Incidence and severity of viral hepatitis in pregnancy. Am J Med 1981;70:252-5.

7. Koff RS. Liver disease in primary care medicine. New York: AppletonCentury-Croft, 1980:40-55.

8. Whelton MJ, Sherlock S. Pregnancy in patients with hepatic cirrhosis: management and outcome. Lancet 1968;ii:995-8.

9. Zimmerman HJ. Drug induced liver disease. In: Hepatotoxicity: The Adverse Effects of Drug and Other Chemicals on the Liver. New York: Appleton- Century-Croft, 1978:349-69.

10. Sheehan HL. Pathology of acute yellow atrophy and delayed chloroform poisoning. J Obstet Gynaecol Br Emp $1940 ; 47: 49-62$.

11. Varner M., Rinderknecht NK. Acute fatty metamorphosis of pregnancy, a maternal mortality and literature review. J Reprod Med 1980;24:177-80.

12. Moldin P, Johansson O. Acute fatty liver of pregnancy with disseminated intravascular coagulation. Acta Obstet Gynecol Scand 1978;57:179-81.

13. Koff RS. Case records of Massachusetts General Hospital. N Engl J Med 1981;304:216-24.

14. Hatfield AK, Stein JH, Greenberger NJ, et al. Idiopathic acute fatty liver of pregnancy, death from extrahepatic manifestations. Dig Dis 1972;17:167-78.

15. Ober WB, LeCompte PM. Acute fatty metamorphosis of the liver associated with pregnancy. Am J Med 1955; 19:743-58.

16. Davies MH, Wilkinson SP, Hanid MA, et al. Acute liver disease with encephalopathy and renal failure in late pregnancy and early puerperium, a study of fourteen patients. $\mathrm{Br}$ J Obstet Gynaecol 1980;87:1005-14.

17. Kaplan MM. Acute fatty liver of pregnancy. N Engl J Med 1985;313:367-70.

18. Lewis PL, Takeda M, Warren WJ. Obstetric acute yellow atrophy. Report of a case. Obstet Gynecol 1963;22:121-7.

19. Eisele JW, Barker EA, Smuckler EA. Lipid content in the liver of fatty metamorphosis of pregnancy. Am J Pathol 1975;81:545-60.

20. Hoyumpe AM Jr, Greene HL, Dunn GD, et al. Fatty liver: biochemical and clinical considerations. Am J Dig Dis 1975;20:1142-70,

21. Korula J, Malatjalian DA, Badley BWD. Acute fatty liver of pregnancy. Can Med Assoc J 1982;127:575-8.

22. Malatjalian DA, Badley BWD. Acute fatty liver of pregnancy. Light and electron microscopic study. Gastroenterology 1983;84:1384. (Abst)

23. Douvres PA, Rosenthal WS, Metzger P, Tchertkoff V. Acute fatty liver of pregnancy with hepatic coma and Mallory Weiss syndrome: Report of a case. Am J Dig Dis 1965;10:306-13.

24. Pockros PJ, Peters RL, Reynolds TB. Idiopathic fatty liver of pregnancy: Findings in ten cases. Medicine 1984;63:1-11.

25. Reily CA. Acute hepatic failure at term. Postgrad Med 1980;68:118-27.

26. Bernuau J, Degott C, Nouel O, et al. Non-fatal acute fatty liver of pregnancy. Gut 1983;24:340-4.

27. Rolfes DB, Ishak KG. Acute fatty liver of pregnancy: a clinicopathologic study of 35 cases. Hepatology 1985;5:1149-58.

28. Breen KJ, Perkins KW, Schenker S, et al. Uncomplicated subsequent pregnancy after idiopathic fatty liver of pregnancy. Obstet Gynecol 1972;40:813-5.

29. Burroughs AK, Seong NH, Dojcinon $\mathrm{DM}$, et al. Idiopathic acute fatty liver of pregnancy in 12 patients. Q J Med 1982;204:481-97.

30. Sherlock S. Acute fatty liver of pregnancy and microvesicular fatty disease. Gut 1983;24:265-9.

31. Reily CA. Acute fatty liver of pregnancy. Semin Liver Dis 1987;7:47-54.

32. Watson WJ, Seeds JW. Acute fatty liver of pregnancy. Obst Gynecol Surv 1990;45:585-93.

33. Kobayshi T, Terao T. Preeclampsia as chronic disseminated intravascular coagulation. Gynecol Obstet Invest 1987;24:170-8.

34. Weiner CP, Xu C, Kwaan $\mathrm{H}$, et al. Antithrombin III in women with hypertension during pregnancy. Obstet Gynecol 1985;65:301-6.

35. Minakami H, Oka N, Sato T, et al. Preeclampsia: a microvesicular fatty disease of the liver. Am J Obstet Gynecol 1988;159:1043-7.

36. Douvas SG, Meeks R, Phillips O, et al. Liver disease in pregnancy. Obstet Gynecol Surv 1983;38:531-6.

37. Brown MS, Reddy KR, Hensley GT, et al. The initial presentation of fatty liver of pregnancy mimicking acute viral hepatitis. Am J Gastroenterol 1987;82:554-7.

38. Shabot JM, Joynes C, Little HM, et al. Viral hepatitis in pregnancy with disseminated intravascular coagulation and hypoglycemia. South Med J 1978;71:479-81.

39. Dill LV. Acute yellow atrophy of the liver associated with pregnancy: a review of the literature and six cases. Obstet Gynecol Surv 1950;5:139-58.

40. Krejs GJ. Jaundice during pregnancy. Semin Liver Dis 1983;3:73-82.

41. Grunfeld JP, Pertuiset N. Acute renal failure in pregnancy. Adv Exp Med Biol 1987;212:245-50.

42. Morrin PA, Handa SP, Valberg LS, et al. Acute renal failure in association with fatty liver of pregnancy. Recovery after fourteen days of complete anuria. Am J Med 1967;42:844-51.

43. Cammu H, Velkeniers B, Charles K, et al. Idiopathic acute fatty liver of pregnancy associated with transient diabetes insipidus. Br J Obst Gynaecol 1987;94:173-8.

44. Ockner SA, Brunt EM, Cohn SM, et al. Fulminant hepatic failure caused by acute fatty liver of pregnancy treated by orthotopic liver transplantation. Hepatology 1990;11:59-64. 


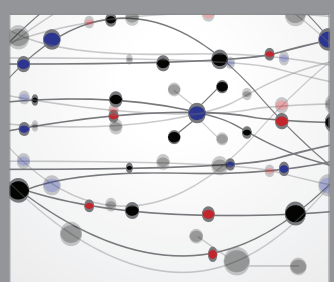

The Scientific World Journal
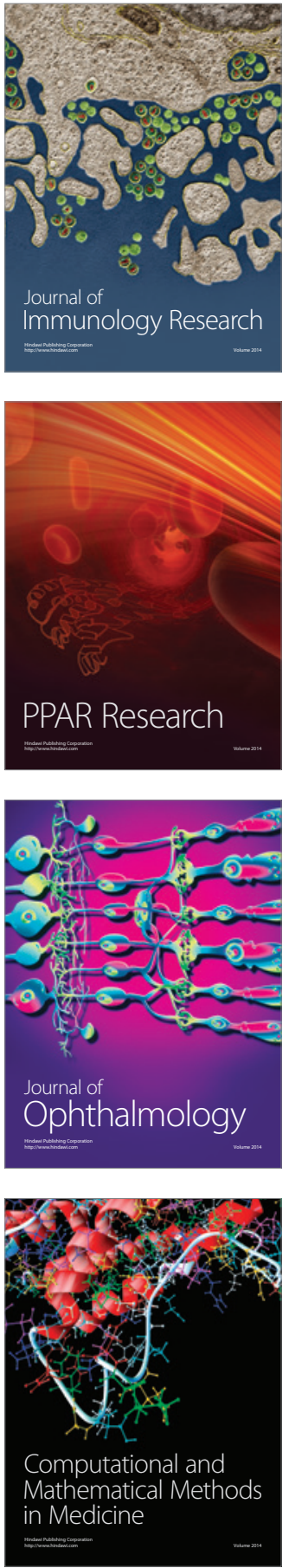

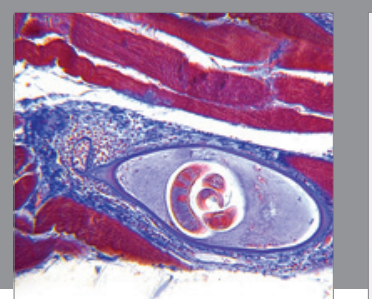

Gastroenterology Research and Practice

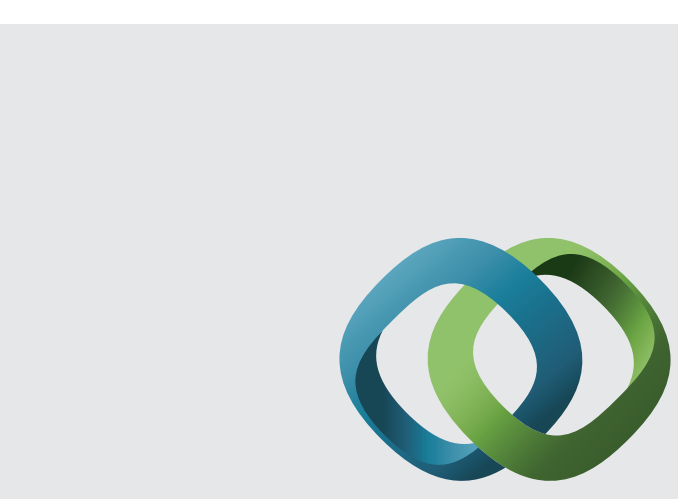

\section{Hindawi}

Submit your manuscripts at

http://www.hindawi.com
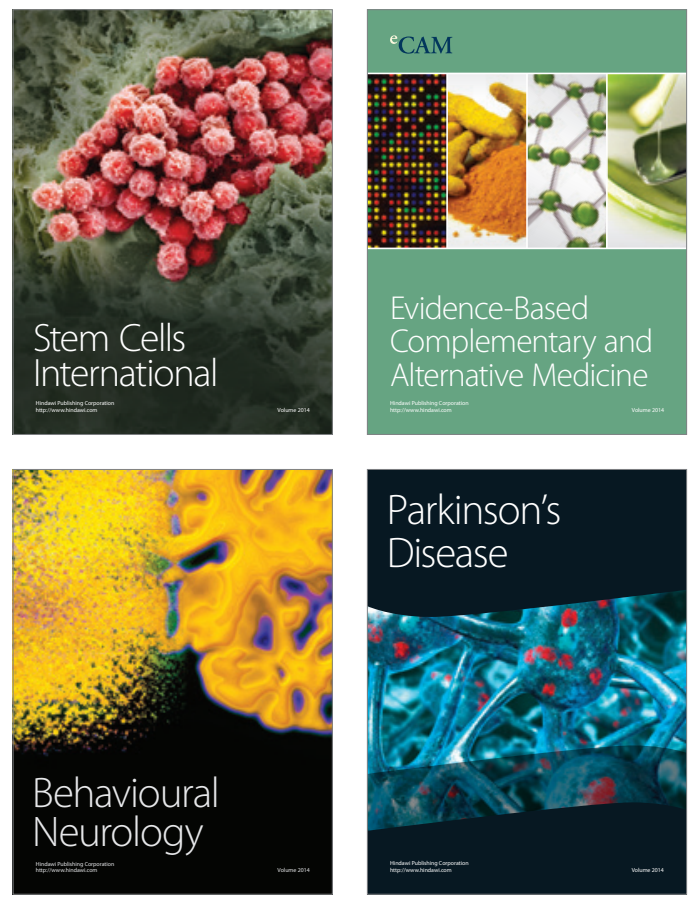
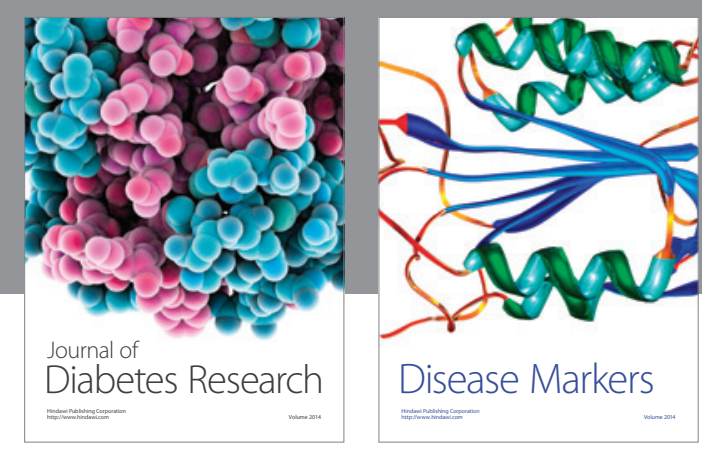

Disease Markers
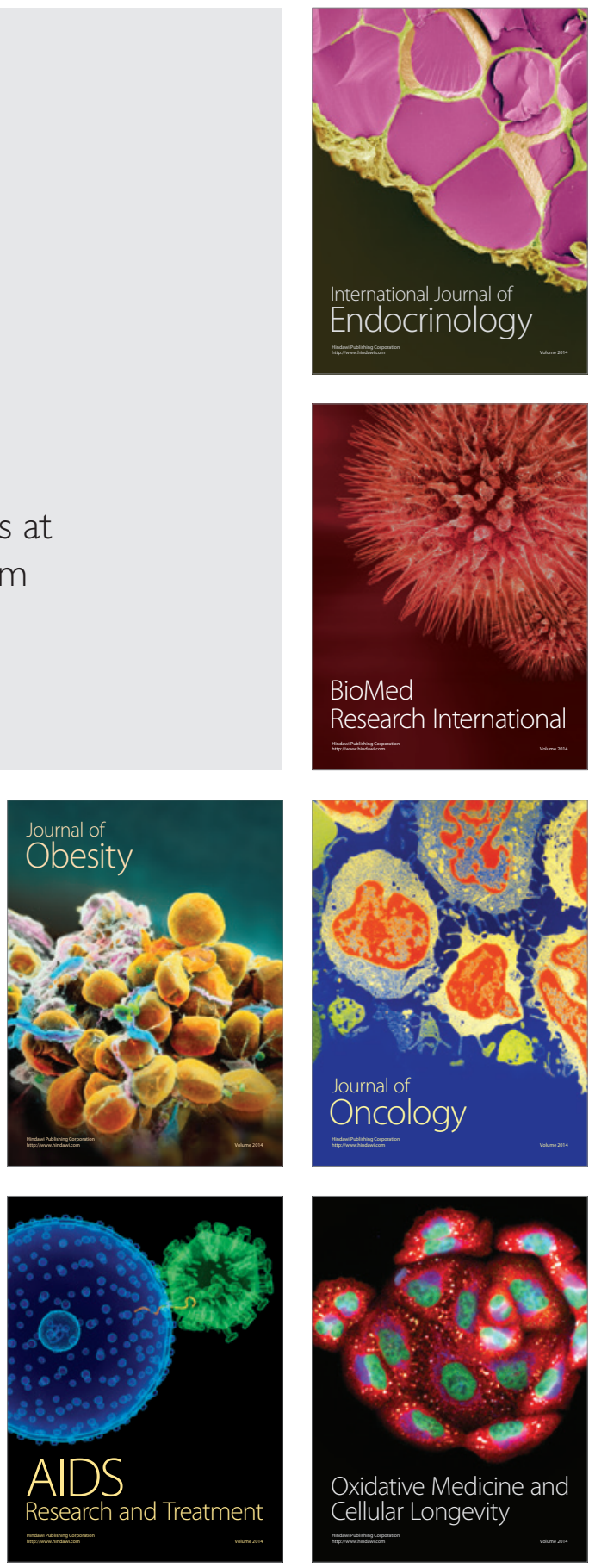